\title{
Difficult Airway Management in Patients with Severe Post Burn Contracture of Neck
}

\author{
Case Report \\ Sarvesh $^{1 *}$, Shalini Chaudhary ${ }^{2}$ \\ ${ }^{1}$ Asssistant Professor, Department of Anaesthesia, B.P.S. Govt. Medical College for women, Khanpurkalan, Sonepat, Haryana, India. \\ ${ }^{2}$ Assistant Professor, Department of Anatomy, B.P.S.G.M.C. KhanpurKalan, sonepat, Haryana, India.
}

\begin{abstract}
Severe anterior post-burn contracture of the neck poses the anaesthesiologist some difficult problems and results in difficult intubation when extension of the atlanto-occipital joint is impaired. Such patients must therefore have the post-burn contracture scar released before other procedures are performed, in order to ensure airway control.

The fiber optic bronchoscope is considered safe and reliable in the difficult endotracheal intubation. Fiber optic bronchoscopy is felt to be the technique of choice when intubation is difficult especially when there are contractures or deformities of the larynx, manidible, or cervical spine.
\end{abstract}

Keywords: Post-Burn Contracture; Fiber optic bronchoscopy.

\section{*Corresponding Author:}

Sarvesh M.D,

Department of Anaesthesia, B.P.S. Govt. Medical College for women, Khanpurkalan, Sonepat (131305), Haryana, India.

Tel: 09728816828

E-Mail: dr_chaudhary23@rediffmail.com

Received: February 10, 2015

Accepted: March 17, 2015

Published: April 01, 2015

Citation: Sarvesh, Shalini Chaudhary (2015) Difficult Airway Management In Patients With Severe Post Burn Contracture of Neck. Int J Anesth Res. 3(3), 93-95. doi: http://dx.doi.org/10.19070/2332-2780-1500024

Copyright: Sarvesh ${ }^{\odot}$ 2015. This is an open-access article distributed under the terms of the Creative Commons Attribution License, which permits unrestricted use, distribution and reproduction in any medium, provided the original author and source are credited.

\section{Introduction}

Severe post-burn contracture (PBC) of the neck represents a challenge to the plastic surgeon as well as the anaesthesiologist. As mortality and morbidity are directly related to the ability to deliver oxygen to the patient, the airway must be managed with particular care in these patients. A burn scar contracture causes insufficient neck extension, resulting in difficult intubation that can be life-threatening [1].

Historically, the intubating laryngeal mask airway, esophageal tracheal Combitube, and retrograde wire technique, have all been used successfully tointubateburn patients [2,3]. Additionally, surgical release of the circumoral and mentosternal contractures, while maintaining spontaneous ventilation under general anesthesia has been described [4]. However, the use of awake blind or fiber optic bronchoscopy, although well recognized as an airway management technique, is yet to establish its role in the burn patient population [5].

Direct laryngoscopy may be hampered by the presence of limited cervical extension. However, in patients with extreme deformity, the functional and anatomical distortion may be such that all attempts at intubation may fail [6].

This paper describes our experience with safe and quick surgical neck release to facilitate orotracheal intubation in such patients.

\section{Case Series}

Between January to November 2007, we enrolled 5 otherwise healthy patients with post burn contractures of the neck. This is a condition in which the neck is contracted in the flexed position and the chin is occasionally restrained down to the anterior trunk, restricting neck motility and preventing extension of the atlanto occipital joint (Figure. 1). Four of the patients had the contracture released under ketamine anesthesia after a failed attempt of orotracheal intubation.

Before anesthesia induction, the neck and thigh of the patients were prepared and draped. Following intravenous induction using ketamine, $1-2 \mathrm{mg} / \mathrm{kg}$ body weight, anaesthesia was maintained by inhalation of oxygen and halothane via a mask to the spontaneously breathing patient. Direct laryngoscopy and orotracheal intubation (Figure. 2) were then tried and, if unsuccessful, a transverse incision over the entire scar was made by a scalpel into the skin and the platysmato facilitate theorotracheal intubation.

At the end of the procedure, halothane was suspended and the muscle relaxant was reversed using neostimine and atropine. Ex- 
Figure 1. Patient with severe post burn contracture of neck.

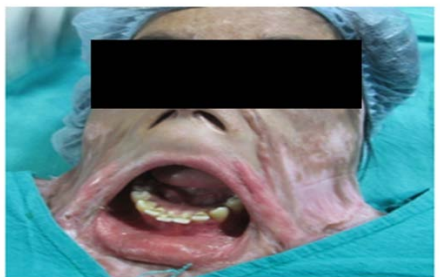

Figure 2. Successful orotracheal intubation.

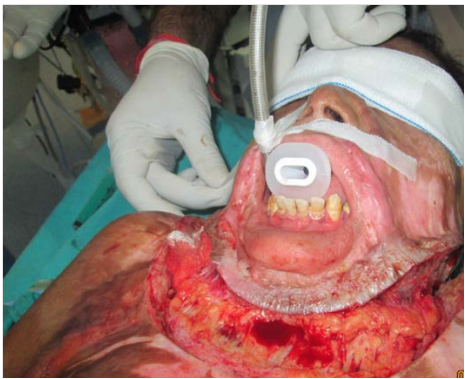

tubation was performed when the patient was awake. Pulse oximetry, ECG, and non-invasive blood pressure monitoring were used during the operation.

All the patients were monitored $24 \mathrm{~h}$ a day for any complications and they were allowed to take oral fluid on the first post-operative day. The patients were kept in a supine position with neck hyperextension by placing pillows under the shoulder. Post-operative splinting and physiotherapy were instituted to prevent recurrence of the contracture.

\section{Discussion}

Post burn contractures of the neck cause functional limitations and aesthetic disfigurements. Securing airway in patients with post-burn contractures of the face and neck is the most challenging problem in reconstructive surgery. The larynx and mandible may be distorted by underlying dense fibrous hypertrophic scar. Cervical range of motion may be limited in all directions and the sniffing position may be unobtainable due to severe mentosternal contracture. The mandible may be displaced posteriorly with accompanying restrictions in mobility. Facial burns during early childhood can cause underdevelopment of the jaw (micrognathia), leading to further distortion of the upper airway [7].

Patients who have suffered deep burns of the anterior thorax with ascending involvement of the neck and face are particularly likely to give rise to problems with orotracheal intubation.

Measurement of the thyromental distance, the Mallampati score and the mouth opening (interdental) distance are important clinical assessment data helping to anticipate difficult intubation [8]. When difficult intubation is expected, a variety of other techniques and instruments can be utilized such as the laryngeal mask, the oesophageo-tracheal Combi tube, the fiber optic bronchoscopy and tracheostomy [8].

Evaluation of the airway should be done in sitting position, not supine or semi-Fowler's. The anesthesiologist should examine the scar and contracture, paying special attention to the perinasal and circumoral regions and the size of the nasal and oral orifices. Scar pattern with its direction and formations may determine the route

\section{of choice of intubation.}

Each intubation technique has potential benefits and drawbacks, but fiberoptic bronchoscopy is felt to be the technique of choice when intubation is difficult [9], especially, when there are contractures or deformities of the larynx, manidible or cervical spine. Video-assisted laryngoscopy can also be a good alternative for airway management in post-burn head and neck scar contracture [10].

We released the contracture under ketamine, achieving complete extension. It is important for a qualified anaestheia provider to be present throughout the procedure to monitor the patient and be ready to intervene for possible surgical release or emergent tracheostomy. The incised wound should be covered with sterile gauze to avoid high risk of wound contamination after neck release.

\section{Conclusion}

Awareness, vigilance and preparedness is the key to successful anesthesia management in post-burn patients. Preoperative judicious evaluation of the scar and airway is mandatory. It is important to keep in mind that underlying functional and anatomical alterations may be significant and lead to extreme deformities interfering with endotracheal intubation.

Proper preoperative patient evaluation and decision to release surgically the neck contracture will halp to successfully secure the airways of post-burn patients with anticipated difficult intubation and reduce anesthetic morbidity and mortality.

\section{References}

[1]. Pawan A (2004) Safe method for release of severe post-burn neck contracture under tumescent local anesthesia and ketamine. Indian J.P. S 37: 51-4.

[2]. Hagberg C, Johnson S, Pillai D (2003) Effective use of the esophageal tracheal Combitube ${ }^{\mathrm{TM}}$ following severe burn injury. J Clin Anesth 15: 463-466.

[3]. Kumar R, Prashast, Wadhwa A (2002) The upside down intubating laryngeal mask airway: A technique for cases of fixed flexed neck deformity. Anesth Analg 95: 1454-1458

[4]. Kreulen M, Mackie DP, Kreis RW, Groenevelt F (1996) Surgical release for intubation purposes in post-burn contractures of the neck. Burns 22: $310-312$.

[5]. (2003) Practice guidelines for management of the difficult airway: an up- 
dated report by the American Society of Anesthesiologists Task Force on Management of the Difficult Airway. Anesthesiology 98: 1269-1277

[6]. Kreulen M, Mackie D, Kreis R, Groenevelt F (1996) Surgical release for intubation purposes in post-burn contracture of the neck. Burns 22: 310-2.

[7]. Nahlieli O, Kelly JP, Baruchin AM, Ben-Meir P, Shapira Y (1995) Oro-maxillofacial skeletal deformities resulting from burn scar contractures of the face and neck. Burns 21: 65-69.

[8]. Ovassapian A, Yelich S, Dykis M, Brunner E (1983) Fiber opticnas otracheal intubation - incidence and causes of failure. Anesth Analg 62: 692-5.

[9]. Xue FS, Liao X, Li CW, Xu YC, Yang QY, et al. (2008) Clinical experience of airway management and tracheal intubation under general anesthesia in patients with scar contracture of the neck. Chin Med J (Engl) 121: 989-997.

[10]. Turkstra TP, Craen RA, Pelz DM, Gelb AW (2005) Cervical spine motion: a fluoroscopic comparison during intubation with Lighted Stylet, GlideScope, and acintoshlaryngoscope. AnesthAnalg 101: 910-915. 